\title{
Reference gene selection and RNA preservation protocol in the cat flea, Ctenocephalides felis, for gene expression studies.
}

\begin{tabular}{|r|l|}
\hline Journal: & Parasitology \\
\hline Manuscript ID & PAR-2016-0105.R1 \\
\hline Manuscript Type: & Research Article - Standard \\
\hline Date Submitted by the Author: & O2-May-2016 \\
\hline Complete List of Authors: & $\begin{array}{l}\text { McIntosh, Catriona; Univ of Aberdeen, Institute of Biological and } \\
\text { Environmental Sciences } \\
\text { Baird, John; University of Aberdeen, School of Biological Sciences } \\
\text { (Zoology) } \\
\text { Zinser, Erich; Zoetis, Global Parasitology Research } \\
\text { Woods, Debra; Zoetis, Global Parasitology Research } \\
\text { Campbell, Ewan; Univ of Aberdeen, School of Biological Sciences } \\
\text { Bowman, Alan; University of Aberdeen, Institute of Biological and } \\
\text { Environmental Sciences; University of Aberdeen, School of Biological } \\
\text { Sciences (Zoology) }\end{array}$ \\
\hline Key Words: & $\begin{array}{l}\text { Ctenocephalides felis, quantitative real-time PCR, normalization, RNA, gene } \\
\text { expression, cat flea, RNA quality, RNA degradation }\end{array}$ \\
\hline
\end{tabular}

\section{SCHOLARONE}

Manuscripts 
1 Reference gene selection and RNA preservation protocol in the cat flea,

2 Ctenocephalides felis, for gene expression studies.

8 Authors: Catriona H McIntosh ${ }^{\mathrm{a}}$, John Baird ${ }^{\mathrm{a}}$, Erich Zinser ${ }^{\mathrm{b}}$, Debra J. Woods ${ }^{\mathrm{b}}$, Ewan M

9 Campbell $^{\mathrm{a}}$, Alan S Bowman ${ }^{\mathrm{a}}$

12 Avenue, Aberdeen AB24 2TZ, UK

$13{ }^{\mathrm{b}}$ Zoetis Inc., 333 Portage Street, Kalamazoo, MI 49007, USA

15 Running title: Reference genes for the cat flea.

\section{Corresponding Author:}

17 


\section{SUMMARY}

30 The cat flea, Ctenocephalides felis, is a major pest species on companion animals thus of 31 significant importance to the animal health industry. The aim of this study was to develop 32 sampling and storage protocols and identify stable reference genes for gene expression 33 studies to fully utilise the growing body of molecular knowledge of $C$. felis. RNA integrity 34 was assessed in adult and larvae samples, which were either pierced or not pierced and stored 35 in RNAlater at ambient temperature. RNA quality was maintained best in pierced samples, 36 with negligible degradation evident after 10 days. RNA quality from non-pierced samples 37 was poor within 3 days. Ten candidate reference genes were evaluated for their stability 38 across four group comparisons (developmental stages, genders, feeding statuses and 39 insecticide-treatment statuses). Glyceraldehyde 3 phosphate dehydrogenase (GAPDH), 60S 40 ribosomal protein L19 (RPL19) and elongation factor-1 $\alpha$ (Ef) were ranked highly in all 41 stability comparisons, thus are recommended as reference genes under similar conditions. 42 Employing just two of these three stable reference genes was sufficient for accurate 43 normalization. Our results make a significant contribution to the future of gene expression 44 studies in C. felis, describing validated sample preparation procedures and reference genes for 45 use in this common pest.

47 Key words: Ctenocephalides felis, quantitative real-time PCR, normalization, RNA, gene 48 expression, cat flea, RNA quality, RNA degradation 
50 KEY FINDINGS

51 - Piercing C. felis samples in RNA-stabilizing solutions is critical to maintain RNA 52 quality

53 - GAPDH, Elongation factor $1 \alpha$ and RPL19 are the most stable reference genes in $C$. 54 felis

55 - The above three genes are stable across life stages, feeding status and insecticide 56 treatment

57 Employing just two of these three stable reference genes was sufficient for accurate 58 normalization.

59 - Case study of vitellogenin expression demonstrates necessity to use multiple reference 60 genes

61 


\section{INTRODUCTION}

63 The cat flea, Ctenocephalides felis, is one of the most common ectoparasites infesting 64 companion animals worldwide and is of major importance to pet owners and the animal 65 health industry (Rust and Dryden 1997; Beugnet et al. 2014). As well as irritation, cat flea 66 infestations can trigger a severe allergic reaction in companion animals, known as flea allergy 67 dermatitis (FAD), and act as a vector for several bacterial infections, most notably Rickettsia 68 felis, and the parasitic worm Dipylidium caninum (Traversa 2013). For these reasons, and 69 also the potential for current treatments to become ineffective, there is a constant need for 70 more insight into this species. In recent years several cat flea expressed sequence tag (EST) 71 and transcriptome studies have become available (Gaines et al. 2002; Ribeiro et al. 2012; 72 Misof et al. 2014; Green et al. 2015), adding to a growing body of molecular knowledge that 73 opens new opportunities for control. Techniques such as reverse-transcription quantitative 74 real-time PCR (RT-qPCR) can be used to explore gene expression and this information can 75 be used to find new ways to control C. felis.

76 RT-qPCR allows precise measurement of differential gene expression between samples. The 77 sensitivity of the technique makes detection of small changes possible; however it also makes the results susceptible to the introduction of errors from experimental technique, such as differences in initial sample size, RNA extraction efficacy and reverse transcriptase enzyme efficiency during cDNA synthesis. To correct for these errors normalization is performed.

81 Several normalization strategies can be used, such as accounting for the amount of total 82 RNA, standardising sample size, or utilising internal reference genes, which are subject to 83 conditions similar to the mRNA of interest (Huggett et al. 2005). Use of one or more 84 endogenous reference genes has emerged as the preferred method for relative quantification 85 and because they undergo the same processes as the mRNA of interest, reference genes can 86 be used to correct for experimentally-introduced differences between samples (Derveaux et 87 al. 2010). An ideal reference gene would be stably expressed across all experimental groups.

88 While normalization using endogenous reference genes is common, it is often the case that such reference genes are chosen without proper validation. Traditional "housekeeping" genes,

90 such as $\beta$-Actin and glyceraldehyde 3-phosphate dehydrogenase (GAPDH), have frequently

91 been used as reference genes for RT-qPCR without proper assessment of their suitability, 92 largely due to their historic use as controls in less sensitive quantitative approaches such as 93 Northern blotting (Boda et al. 2008). When tested, many commonly used control genes have 
94 been shown to exhibit unstable expression across treatments under various conditions 95 (Thellin et al. 1999). Several studies demonstrating the impact of unstable reference genes on 96 the assessment of target gene expression levels have highlighted the need to validate 97 reference genes for specific experimental design, cell and tissue type (Kidd et al. 2007; Boda 98 et al. 2008; Kosir et al. 2010).

99 The aim of the current study was to develop procedures and tools for working with cat flea 100 specimens at a molecular level. Understanding how storage can impact RNA integrity is vital 101 for implementation of collaboration between research centres, allowing the transfer of 102 reliable RNA between groups. Reliable reference genes are essential for robust gene 103 expression studies (Bustin et al. 2009). Therefore the main tasks were to investigate how 104 sample collection and storage procedures affect integrity of RNA that will be used in 105 downstream gene expression studies and to screen and validate reference genes for use in RT106 qPCR screens in the cat flea. Ten candidate reference genes in C. felis were assessed across 107 the following 4 groups: developmental stage, sex, feeding status (fed versus unfed) and 108 insecticide treatment-status (treated or untreated).

MATERIALS AND METHODS

Insect rearing

111 All C. felis samples were obtained from an artificially reared colony kept by Zoetis Inc 112 (Kalamazoo, MI, USA), developed from fleas supplied by Elward II, California, USA, using 113 methods similar to Kernif et al. (2015). Adults were fed ad libitum on bovine blood, after 114 which eggs were collected three times per week and placed in containers with larval rearing 115 media, consisting of $74 \%$ finely ground laboratory canine diet, $25 \%$ dried Brewer's yeast 116 and $1 \%$ part dried bovine blood, and fine sand. Larval containers were left undisturbed until 117 emergence of adults approximately three weeks after egg collection. All life stages were 118 reared in an insectary at $\approx 26{ }^{\circ} \mathrm{C}$ and $80 \%$ relative humidity with a $12: 12 \mathrm{~L}: \mathrm{D}$ cycle.

\section{Biological samples and cDNA synthesis}

120 Fed adult $C$. felis of mixed ages were collected from adult feeding chambers. Larvae and 121 pupae were collected from culture pots approximately 7 and 12 days post-hatch, respectively.

122 Unfed adults were collected approximately 30 days post-hatch (within 3 days of emergence 123 from pupal case). For insecticide treatment, adults of mixed age were allowed to feed on 1 
$124 \mu \mathrm{M}$ selamectin (Zoetis Inc, USA) in bovine blood for 24 hours prior to collection. Cat flea 125 samples were pierced once, centrally, with a 23 gauge needle, and groups of 10 placed 126 directly in $1 \mathrm{~mL}$ RNAlater (Life Technologies, ThermoFisher Scientific, Grand Island, NY, 127 USA) and kept at $4{ }^{\circ} \mathrm{C}$ overnight before storage at $-80^{\circ} \mathrm{C}$. Samples were sent to the University 128 of Aberdeen, UK, on dry ice. Prior to RNA extraction, pupae were removed from their cases 129 using 23 gauge needles. On the basis of size, females being larger than males, a subset of fed 130 adults were sorted into males and females.

131 For RNA extraction, pools of 3-10 fleas were removed from RNAlater and then homogenised 132 in $1 \mathrm{~mL}$ Tri-reagent (Sigma-Aldrich, UK) by crushing in $1.5 \mathrm{~mL}$ microfuge tubes with 133 micropestles. RNA was extracted according to manufacturer's instructions, with the phase 134 separation and ethanol washes repeated twice. RNA was resuspended in $8 \mu \mathrm{L}$ (selamectin135 treated samples, as fewer fleas were available for RNA extraction) or $20 \mu \mathrm{L}$ RNase-free $\mathrm{H}_{2} \mathrm{O}$ 136 and quantified using a Nanodrop ND-1000 spectrophotometer (Thermo Scientific, 137 Loughborough, UK). RNA was treated with RQ1 DNase (Promega, UK) and $1 \mu \mathrm{g}$ used as 138 template for cDNA synthesis with BioScript reverse transcriptase (Bioline Reagents Limited, 139 London, UK).

140 Assessing influence of sampling procedure and storage conditions on RNA integrity

141 Groups of 10 larvae and fed adults were either pierced once with a 23 gauge needle or not 142 pierced and placed in $1 \mathrm{~mL}$ RNAlater (Life Technologies). All samples were incubated at 4 $143{ }^{\circ} \mathrm{C}$ overnight then stored at room temperature for 0,3 or 10 days before being frozen at -80 $144{ }^{\circ} \mathrm{C}$ until processing. RNA was extracted from groups of 10 fleas, as above. Total RNA 145 concentration was measured using a ND-1000 Nanodrop spectrophotometer (Thermo146 scientific) and RNA quality was assessed using an Agilent 2100 Bioanalyzer and Agilent 147 RNA 6000 Nano kit. Due to a hidden $18 \mathrm{~S} / 28 \mathrm{~S}$ break in the rRNA of many arthropod species 148 (also apparent in C. felis) an accurate RNA Integrity Number (RIN) cannot be calculated 149 (Winnebeck et al. 2010). RNA integrity was therefore assessed by visual inspection of 150 electropherograms for each sample, assessing two replicates for each treatment. The time 151 points of 3 and 10 days were selected for study relates to the approximate time for 152 international courier by air (3 days) and international surface mail (10 days). 
154 Ten reference gene candidates were selected based on housekeeping genes previously used 155 for RT-qPCR in the cat flea (Dreher-Lesnick et al. 2010) or transcripts commonly used as 156 references in other insect species (Scharlaken et al. 2008; Li et al. 2013; Zhai et al. 2014; Tan 157 et al. 2015). Ten candidate primer sets, representing transcripts from different functional 158 classes, were initially assessed (Table 1). Sequences were obtained from annotated sequences 159 in Ribeiro et al. (2012) (18S ribosomal RNA (18S), 28S ribosomal RNA (28S), 60S 160 ribosomal protein (RPL19)), the BLAST Transcriptome Shotgun Assembly database 161 (Elongation factor $1 \alpha$ (Ef), Act ( $\beta$-Actin)), or by using tBLASTn to search the cat flea EST 162 database using Drosophila melanogaster sequences obtained from Flybase (Dos Santos et al. 163 2015) (GAPDH, Heat shock protein 22 (HSP22), NADH dehydrogenase/ ubiquinone 164 reductase (NADH), $\alpha$-Tubulin ( $\alpha$ Tub)). Primer3Plus (http://www.bioinformatics.nl/cgi$165 \mathrm{bin} /$ primer3plus/primer3plus.cgi/) was used for primer design, implementing the qPCR 166 setting and then checked manually. For comparison, a primer set targeting muscle-specific 167 actin (DLAct) used in Dreher-Lesnick et al. (2010) was also included in the analysis. PCR 168 was performed for each primer set using $25 \mu \mathrm{L}$ BioMix Red (Bioline), $22 \mu \mathrm{L} \mathrm{H}_{2} \mathrm{O}, 2 \mu \mathrm{L}$ 169 mixed $C$. felis cDNA and $1 \mu \mathrm{L} 10 \mathrm{mM}$ primer sets. Reactions were performed with the 170 following conditions: $95^{\circ} \mathrm{C} 5 \mathrm{~min}, 35$ cycles of $95{ }^{\circ} \mathrm{C} 30 \mathrm{~s}, 58^{\circ} \mathrm{C} 45 \mathrm{~s}, 72{ }^{\circ} \mathrm{C} 45 \mathrm{~s}$, followed 171 by incubation at $72{ }^{\circ} \mathrm{C}$ for $10 \mathrm{~min}$. PCR products were electrophoresed in a $2 \%$ agarose Tris172 borate-EDTA (TBE) gel to confirm there was a single product of the expected size.

\section{Quantitative real-time PCR}

174 RT-qPCR was carried out in 96-well plates CFX96 Touch Real-Time PCR detection system 175 (Bio-Rad Laboratories, USA). Reactions were run in $20 \mu \mathrm{L}$ volumes (10 $\mu \mathrm{L}$ iTaq Sybr Green 176 supermix (Bio-Rad), $1 \mu \mathrm{L} 10 \mathrm{mM}$ primer mix, $5 \mu \mathrm{L} \mathrm{H}_{2} \mathrm{O}$ and $4 \mu \mathrm{L}$ template cDNA (1/20 177 dilution of cDNA produced from $1 \mu \mathrm{g}$ DNase-treated RNA). PCR cycling conditions were: $17895^{\circ} \mathrm{C} 3 \mathrm{~min}, 40$ cycles of $95{ }^{\circ} \mathrm{C} 10 \mathrm{~s}, 58^{\circ} \mathrm{C} 30 \mathrm{~s}$ followed by a melt-curve analysis step 179 consisting of $0.5{ }^{\circ} \mathrm{C}$ incremental rises every $5 \mathrm{~s}$, rising from $65^{\circ} \mathrm{C}$ to $95{ }^{\circ} \mathrm{C}$. No template 180 controls in duplicate were run for each primer set. Three replicates were run in triplicate for 181 each treatment, except unfed and fed adults, where two and four replicates were used, 182 respectively. Four-step 10-fold serial dilutions of mixed standard cDNA were performed in 183 duplicate to create standard curves to calculate primer efficiencies. CFX manager software 184 (version 3.1) (Biorad) was used to calculate efficiencies from a standard serial dilution curve. 
185 Melt-curve analysis utilised CFX manager software to confirm correct product profiles for 186 each primer set and $\mathrm{Cq}$ values extracted for further analysis.

\section{Data analysis}

188 Reference gene stability was assessed using three software programmes: geNorm (version 189 3.4) (Vandesompele et al. 2002), Normfinder (version 0.953) (Andersen et al. 2004) and 190 Bestkeeper (version 1.0) (Pfaffl et al. 2004). Cq values were transformed using the delta-Ct 191 method for analysis in GeNorm. For Normfinder, Cq values were transformed to a linear 192 scale using the calculation $(2 \mathrm{E})^{-\mathrm{Cq}} \cdot \mathrm{Cq}$ and efficiency values were input directly into 193 Bestkeeper.

194 GeNorm ranks reference genes from most to least stable by calculating the gene expression 195 stability $\mathrm{M}$, the average pairwise variation of the expression ratio of a particular gene 196 compared to all other tested genes (Vandesompele et al. 2002). Low M value is indicative of 197 gene stability, with $\mathrm{M}<1.5$ necessary for utility as a reference gene. GeNorm gives two 198 informative outputs. Firstly, a ranking of genes in order of stability based on calculation of 199 average $\mathrm{M}$ for all genes and step-wise exclusion of the least stable gene and recalculation of 200 the average M. Secondly, stability rankings generated from geNorm software can be used to 201 assess the number of reference genes needed for accurate normalization, based on the 202 pairwise variation $\left(\mathrm{V}_{\mathrm{n}} / \mathrm{V}_{\mathrm{n}+1}\right)$ between sequential normalization factors, based on geometric 203 means of the most stable genes which is recalculated following addition of each subsequent 204 gene. The lowest number of genes giving $\mathrm{V}_{\mathrm{n}} / \mathrm{V}_{\mathrm{n}+1}<0.15$ is the minimal number that should 205 be used for normalization.

206 Normfinder utilises a model-based approach to assess reference gene stability, based on 207 measures on intra- and inter-group variations, which are based on user-specified groupings 208 (Andersen et al. 2004). This generates a stability value (SV) for each gene, as well as for the 209 best combination of two reference genes. Low SV is indicative of gene stability, with SV $>1$ 210 suggesting a candidate is unstable and not suitable for use as a reference gene.

211 Bestkeeper uses input $\mathrm{Cq}$ and efficiency data to generate descriptive statistics for each gene, 212 before generating a Bestkeeper index value (r) for each sample based on the geometric mean 213 of its $\mathrm{Cq}$ values for each reference gene tested (Pfaffl et al. 2004). Stability can be assessed, 214 based on standard deviation (SD) $\pm \mathrm{Cq}$ and coefficient of variation. Only candidates where $215 \mathrm{SD} \pm \mathrm{Cq}$ is $<1$ are suitable for use as reference genes. 
216 Analysis was conducted in each of the programmes to assess reference genes most suitable

217 for use in four groups: Developmental stages (larvae vs pupae vs unfed adults vs fed adults),

218 Sexes (male vs female fed adults), Feeding statuses (fed vs unfed adults) and Treatment 219 statuses (selamectin treated vs untreated fed adults). An overall ranking was produced using a 220 points-based system to combine the rankings from all of the programmes used.

221 Validation of reference genes - a case study in vitellogenin C expression

222 Vitellogenins are key components of yolk in insect, produced in the fat body of adult females 223 (Pan et al. 1969). Due to this function it is expected that levels of vitellogenin transcripts will 224 be significantly higher in females than in males. The expected large difference made this a 225 promising target to validate candidate reference genes for their utility in normalization. 226 Primers were designed from an EST sequence representing vitellogenin C (Ribeiro et al. 227 2012), tested for specificity by melt-curve analysis and PCR followed by gel electrophoresis 228 to confirm a single product of the expected size was produced (Table 1). The efficiency of 229 this primer set was assessed by creating a standard curve using CFX Manager software 230 (version 3.1) (Biorad) from duplicate 4-step 10-fold serial dilutions of mixed standard C. felis 231 cDNA. RT-qPCR was performed to measure the expression of vitellogenin in samples from 232 male $(\mathrm{n}=3)$ and female $(\mathrm{n}=3)$ fed adult $C$. felis, and normalized using the best single 233 reference genes (GAPDH, Ef), best two reference genes (GAPDH + Ef), best three reference 234 genes (GAPDH + Ef + RPL19) or least stable reference gene (18S) as listed in the overall 235 ranking of reference genes for this comparison (Table 2). First the R0 for each sample was 236 calculated for each gene for each sample using the equation $\mathrm{R} 0=1 /(1+\mathrm{E})^{\mathrm{Cq}}$, then the 237 normalized values were calculated by dividing Vit R0 by the reference gene R0 or geometric 238 mean of R0 for normalization with multiple reference genes.

\section{RESULTS}

241 The electropherograms for pierced larvae and adult samples are similar after 0, 3 and 10 days 242 storage in RNAlater at room temperature (Fig. 1), with no appreciable accumulation of small

243 RNA fragments visible. In contrast, degradation was clear in unpierced samples within 3 244 days, particularly in larvae samples (Fig. 1B). By day 10 at room temperature the majority of 245 large RNA transcripts appeared to be fragmented, demonstrating RNA quality had dropped 246 significantly. 
248 Primer efficiencies ranged from 83.5-97.5\%, with most primer sets having efficiency greater 249 than $90 \%$. The DLAct primers had a lower efficiency than preferable $(83.5 \%)$ and would 250 have been discarded based on normal acceptable efficiency criteria. However, the DLAct 251 primers were still used in reference gene testing for comparison due to their prior use in a 252 publication (Dreher-Lesnick et al. 2010). NADH primers were not used for further analysis 253 due to their highly variable efficiency $(\mathrm{E}=90.7 \%, \mathrm{SD}=16.7 \%)$.

$254 \mathrm{Cq}$ values across all treatment samples (Mean $\pm \mathrm{SD}, \mathrm{n}=30$ ) for the 9 analysed reference 255 genes ranged from $15.34 \pm 1.65$ (28S) to $22.44 \pm 1.34$ ( $\alpha$-Tubulin) (Fig. 2). GAPDH was the 256 least variable reference gene tested across all samples (coefficient of variation $(\mathrm{CV})=3.45$ $257 \%)$, while $28 \mathrm{~S}$ was the most variable $(\mathrm{CV}=10.93 \%)$. Several genes $(18 \mathrm{~S}, 28 \mathrm{~S}$, DLAct $)$ had 258 clear outlying values, which suggested instability (Fig. 2).

Expression stability of reference genes across developmental stages

260 Three software programs were used to rank the nine candidate reference genes in C. felis for 261 their stability across different developmental stages (larvae $n=3$, pupae $n=3$, unfed adults $n$ $262=2$, fed adults $\mathrm{n}=3$; throughout the study $\mathrm{n}=$ number of pooled samples tested, each pool 263 contained between 3 and 10 fleas) (Table 2). GeNorm ranked the genes based on their 264 average expression stability (M), calculating this value with all genes included then removing 265 the least stable gene and recalculating $M$ until only two genes remain which cannot be further differentiated (Fig. 3). Ef and RPL19 were identified as the most stable genes by geNorm (M $=0.132)$ and $28 \mathrm{~S}$ the least stable $(\mathrm{M}=1.203)$ (Table 2, Fig. 3). However, all genes tested had $\mathrm{M}<1.5$ therefore can be considered stable enough to use as reference genes according to this analysis. A pairwise variation analysis between normalization factors $V_{n} / V_{n+1}$ was also performed by geNorm to assess the minimal number of reference genes needed for accurate normalization. Pairwise variation $(\mathrm{V})<0.15$ indicates additional reference genes are

272 unnecessary. For comparisons across all developmental stages V2/3 V $=0.048$, indicating

273 two reference genes are sufficient for normalization in this case (Fig. 4) and no significant 274 benefit is gained by using $>2$ reference genes.

275 The best gene determined by Normfinder analysis for comparisons between developmental $C$. 276 felis groups was RPL19 $(\mathrm{SV}=0.270)$ and the best combination of two genes was actin and 277 GAPDH $(\mathrm{SV}=0.210)$ (Table 2). HSP and 28S were found to be the least stable genes, with 
278 SV $>1$ suggesting they were unsuitable for use as reference genes in C. felis studies (Table $2792)$.

$280 \mathrm{Cq}$ and efficiency values were input into Bestkeeper to produce descriptive statistics. The 281 standard deviation \pm Crossing Point $(\mathrm{SD} \pm \mathrm{CP})$ can be used to rank stability. Under this 282 criteria $18 \mathrm{~S}$ was ranked as the most stable $C$. felis gene ( $\mathrm{SD} \pm \mathrm{CP}=0.54$ ), followed by 283 GAPDH $(\mathrm{SD}=0.63)$ and $\mathrm{Ef}(\mathrm{SD}=0.76)$. HSP was the least stable gene $(\mathrm{SD}=1.89)$ and 284 considered too unstable for use as a reference gene as it had $\mathrm{SD}>1$.

285 The rankings for each program were combined using a points-based system to estimate an 286 overall ranking of reference gene stability. This ranking found Ef, RPL19 and Act to be the 287 most stable genes across C. felis developmental stages and 28S and HSP to be the least stable 288 candidates (Table 2).

290 Comparing the stability of candidate reference genes between male $(\mathrm{n}=3)$ and female $(\mathrm{n}=3)$ 291 fed C. felis adults, geNorm ranked GAPDH and RPL19 as the most stable $(\mathrm{M}=0.112$ ) (Table 292 2, Fig. 3). 18S was the least stable gene based on this comparison; although all genes had M $293<1.5$ therefore can be considered as potentially suitable reference genes in C. felis. Pairwise 294 comparison of normalization factors suggested two genes are sufficient for accurate 295 normalization $(\mathrm{V}=0.049)$ (Fig. 4). Normfinder ranked GAPDH as the most stable gene (SV $296=0.144)$, Act and Ef as the best combination of two genes (SV = 0.111) and DLAct the least 297 stable $(\mathrm{SV}=0.510)$ (Table 2). DLAct was ranked as the most stable gene by Bestkeeper (SD $298=0.51)$, while suggesting $18 \mathrm{~S}$, HSP and $\alpha \mathrm{Tub}$ are unsuitable as reference genes $(\mathrm{SD}>1)$. The 299 combined overall ranking placed GAPDH, Ef and RPL19 as the most stable candidate 300 reference genes across C. felis and $18 \mathrm{~S}$ as the least stable (Table 2).

301 Expression stability of reference genes across feeding statuses

302 GeNorm ranked Act and Ef as the most stable genes across feeding statuses (unfed adults $\mathrm{n}=$ 303 2, fed adults $\mathrm{n}=4)(\mathrm{M}=0.112)$ (Table 2). Two genes were found to be sufficient for 304 normalization (Fig. 4). 18S was the least stable gene according to both geNorm and 305 Normfinder. Normfinder placed GAPDH as the most stable gene (SV =0.092) and GAPDH 306 and RPL19 to be the best combination of two genes (SV =0.065). Bestkeeper estimated 28S 307 and DLAct as the most and least stable genes respectively. Each candidate met the 308 requirements to be classed as a suitable reference gene by all programs in this comparison. 
309 The overall points-system ranking placed RPL19, GAPDH and Ef as the most stable

310 reference genes across fed and unfed $C$. felis adults and $18 \mathrm{~S}$ as the least stable candidate.

\section{Expression stability of reference genes across insecticide treatment statuses}

312 Stability of reference genes across treated $(1 \mu \mathrm{M}$ selamectin, $\mathrm{n}=3)$ and untreated $(\mathrm{n}=3)$ fed

313 adult $C$. felis was investigated. Act and RPL19 were the most stable candidates according to 314 geNorm $(\mathrm{M}=0.104)$ (Table 2, Fig. 3). Bestkeeper also ranked these as the top two reference 315 genes (Table 2). Two candidates were estimated to be sufficient for accurate normalization $316(\mathrm{~V}=0.150)$ (Fig. 4). Ef $(\mathrm{SV}=0.035)$ or a combination of Ef and $\alpha \mathrm{Tub}(\mathrm{SV}=0.042)$ were the 317 best candidates according to Normfinder (Table 2). All programmes ranked 18S as the least 318 stable gene across treatment statuses, with geNorm and Bestkeeper both classing it as 319 unsuitable for use as a reference gene. Bestkeeper also found $\alpha \mathrm{Tub}$, DLAct and $28 \mathrm{~S}$ to be 320 unsuitable candidates, perhaps because samples within this group account for several of the 321 outliers seen in Fig. 2, which are likely to lead to a high standard deviation. The most stable 322 genes in the overall ranking were Act, RPL19 and GAPDH, with 18S as the least stable 323 candidate by this estimate.

324 Validation of reference genes - a case study in vitellogenin C levels across sexes

325 In all cases vitellogenin $\mathrm{C}$ was found to be upregulated in females relative to males, with 326 reported fold-changes ranging from $8.46 \mathrm{x}$ to $12.32 \mathrm{x}$ (Fig. 5). Normalization with the two best 327 reference genes individually led to disagreement in fold-change $(\mathrm{GAPDH}=8.46 \mathrm{x}, \mathrm{Ef}=$ $32811.08 \mathrm{x}$ ), whereas results were more consistent when using 2 or 3 reference genes in 329 combination $(9.69 \mathrm{x} \pm 1.07 \& 9.32 \mathrm{x} \pm 0.80)$ respectively). The coefficient of variation of the 330 normalised fold change was much higher when using the least stable gene (18S) to normalise $331(37.98 \%)$ compared to any of the combinations of single of multiple more stable genes, 332 where the coefficient of variation ranged from $8.60-12.70 \%$.

\section{DISCUSSION}

334 RNA samples are highly susceptible to breakdown from endogenous RNases following 335 collection. RNAlater, a high density salt solution, acts to stabilise RNA by preventing action 336 of such RNases. In order to work effectively RNAlater must enter tissues (Chen et al. 2007) 337 but external structures, such as fine hairs on the surface of many arthropods, can prevent the 338 solution from contacting internal tissues. Thus, it is often necessary to penetrate the sample 339 tissues for proper exposure to RNAlater. Piercing individual cat fleas is a relatively laborious 
340 process due to their small size and could dissuade some potential collaborators (e.g. 341 veterinarians, kennel staff, the general public) from collecting fleas for downstream gene 342 expression work. Thus, it was investigated if piercing is actually necessary for maintenance 343 of RNA integrity by RNAlater. This study found that penetrating C. felis specimens is 344 essential for preservation of RNA, with degradation clearly apparent in unpierced larvae and 345 adult samples after even 3 days at room temperature (Fig. 1). However when specimens were 346 pierced prior to submergence in RNAlater they could be stored at room temperature for up to 34710 days with little degradation visible on electropherogram traces. A small peak at around 25 348 seconds was visible in pierced adult electropherograms after 3 and 10 days, representing 349 small RNAs which could be indicative of a small amount of degradation. Thus, samples 350 could be shipped at ambient temperature nationally and internationally for collaboration 351 between research groups, if pierced upon collection and placed in RNAlater. Such an approach may be particularly useful when fleas are to be collected by veterinary practices or

353 pet owners before being passed onto the research organisation. However if a particularly 354 sensitive technique is to be utilized such as RNASeq it may still be beneficial to freeze 355 samples before transportation on dry ice.

356

357 Reference genes which are stable across experimental conditions are essential to reliable 358 interpretation of RT-qPCR data. Although several studies have used RT-qPCR to look at $R$. 359 felis bacterial replication within the cat flea (Henry et al. 2007; Obhiambo et al. 2014), few 360 have utilised the technique to study endogenous cat flea gene expression (Dreher-Lesnick et 361 al. 2010). Past historical "housekeeping genes" have often been used in arthropod studies 362 without proper validation. Recently, systematic screening of candidate reference genes has 363 been performed for many insect species (Scharlaken et al. 2008; Teng et al. 2012; Li et al. 364 2013; Omondi et al. 2015; Shakeel et al. 2015), with many of these studies highlighting the 365 importance of validating references in all experimental conditions and tissues of interest. In 366 this study we systematically assessed ten candidate reference genes for stability within 4 367 groups of C. felis: developmental stages, sexes, feeding statuses and insecticide-treatment 368 statuses. Transcripts commonly used in other insect species were selected for comparison 369 (Scharlaken et al. 2008; Li et al. 2013; Zhai et al. 2014; Tan et al. 2015).

371 Three programs were used to estimate the stability of the candidate reference genes, geNorm, 372 Normfinder and Bestkeeper. Each program uses a different algorithm to assess stability, 
373 leading to differences in the rankings between programmes. This was particularly apparent

374 for Bestkeeper in this study, which often highlighted as the best gene a candidate which was 375 ranked low by other programmes (Table 2). To give an easy guide to stable reference genes 376 an overall ranking was produced for each comparison. This overall ranking showed GAPDH, 377 RPL19 and Ef to rank highly in all comparisons (Table 2). Ribosomal proteins, GAPDH and 378 Ef have all been characterised recently as stable reference genes in other arthropod species 379 (Scharlaken et al. 2008; Teng et al. 2012; Li et al. 2013; Omondi et al. 2015; Shakeel et al. 380 2015). While it is important to assess stability of references in specific experimental 381 conditions, GAPDH, RPL19 and Ef would be recommended as reference genes for any of the 382 comparisons tested here in C. felis.

383

384 The use of unstable reference genes can have a large impact on the interpretation of RT385 qPCR results (Kidd et al. 2007; Boda et al. 2008; Kosir et al. 2010). To validate the ranking 386 of our candidate genes levels of vitellogenin $\mathrm{C}$ in male and female fed adult $C$. felis were 387 investigated, using the best three (GAPDH + Ef + RPL19), two (GAPDH + Ef) or single 388 (GAPDH, Ef) genes and the least stable (18S). Vitellogenin C levels were found to be 389 approximately 9-fold higher in females compared to males. While all normalization strategies 390 demonstrated an increase in vitellogenin $\mathrm{C}$ in females, the estimated fold change varied from 3918.5 -fold to 12.3-fold (Fig. 5). Using the least stable gene for normalization gave a high 392 coefficient of variation (37.98\%) compared to the other normalization strategies (CV 8.60$39312.70 \%$ ), demonstrating the uncertainty introduced by use of an inappropriate reference 394 gene. This is particularly important when trying to detect small changes in gene expression 395 between samples, where instability of a reference gene could lead to misinterpretation of 396 results (Omondi et al. 2015). Use of two or three reference genes generated a more consistent 397 fold change estimate (9.69-fold \& 9.32-fold respectively), with single reference genes 398 generating different estimates $(\mathrm{GAPDH}=8.46 \mathrm{x}, \mathrm{Ef}=11.08 \mathrm{x})$. This highlights the importance 399 of using multiple reference genes for accurate normalization.

400

401 The present study provides insight into sample preparation and reference genes suitable for 402 use across a variety of conditions for $C$. felis specimens. In summary, our findings 403 recommend piercing of $C$. felis before placing in an RNA-stabilizing solution and storing at 404 room temperature and that two reference genes selected from GAPDH, Ef and RPL19 are 405 suitable and suffice for accurate gene expression studies in C. felis in the given experimental 
406

407

408

409

410

411

412

413

414

415

416

417

418

419

420

421

422

423

424

425

426

427

428

429

430

conditions. This paves the way for new investigations into $C$. felis gene expression, opening new avenues for the research community to utilise to find ways to tackle this common pest.

\section{ACKNOWLEDGEMENTS}

Many thanks to Zoetis Inc for providing the cat flea specimens for this analysis.

\section{FINANCIAL SUPPORT}

This work was supported by a Knowledge Transfer Network BBSRC Industrial Case (\# BB/L502467/1) studentship in association Zoetis Inc.

\section{CONFLICT OF INTEREST}

None

\section{REFERENCES}

Andersen C. L., Jensen J. L. and Orntoft T. F. (2004). Normalization of real-time quantitative reverse transcription-PCR data: a mode-based variance estimation approach to identify genes suited for normalization, applied to bladder and colon cancer data sets. Cancer Research 64, 5245-5250. doi:10.1158/0088-5472.CAN-04-0496

\section{Beugnet F., Bourdeau P., Chalvet-Monfray K., Cozma V., Farkas R., Guillot J., Halos}

L., Joachim A., Losson B., Miro G., Otranto D., Renaud M. and Rinaldi L. (2014).

Parasites of domestic cats in Europe: co-infestations and risk factors. Parasites \& Vectors 7: 291. doi: 10-1186/1756-3305-7-291.

Boda E., Pini A., Hoxha E., Parolisi R. and Tempia F. (2008). Selection of reference genes for quantitative real-time RT-PCR studies in mouse brain. Journal of Molecular Neuroscience 37, 238-253. doi: 10.1007/s12031-008-9128-9 
431 Bustin S. A., Benes V., Garson J. A., Hellemans J., Huggett J., Kubista M., Mueller R.,

432 Nolan T., Pfaffl M. W., Shipley G. L., Vandescompele J. and Wittwer C. T. (2009). The

433 MIQE Guidelines: Minimum Information for Publication of Quantitative Real-Time

434 PCR Expermiments. Clinical Chemistry 55, 611-622. doi: 10.1373/clinchem.2008.112797

435 Chen Y., Evans J., Hamilton M. and Feldlaufer M. (2007). The influence of RNA

436 integrity on the detection of honey bee viruses: Molecular assessment of different sample

437 storage methods. Journal of Apicultural Research 46, 81-87. doi:

$438 \quad 10.1080 / 00218839.2007 .11101372$

439 Derveaux S., Vandesompele J. and Hellemans J. (2010). How to do successful gene

440 expression analysis using real-time PCR. Methods 50, 227-230. doi:

$441 \quad 10.1016 /$ j.ymeth.2009.11.001

442 Dos Santos G., Schroeder A. J., Goodman J. L., Strelets V. B., Crosby M. A., Thurmond

443 J., Emmert D. B. and Gelbart W. M. (2015). FlyBase: Introduction of the Drosophila

444 melanogaster release 6 reference genome assembly and large-scale migration of genome

445 annotations. Nucleic Acids Research 43, D690-D697. doi: 10.1093/nar/gku1099

446 Dreher-Lesnick S. M., Ceraul S. M., Lesnick S. C., Gillespie J. J., Anderson J. M.,

447 Jochim R. C., Valenzuela J. G. and Azad A. F. (2010). Analysis of Rickettsia typhi-

448 infected and uninfected cat flea (Ctenocephalides felis) midgut cDNA libraries: deciphering

449 molecular pathways involved in host response to R. typhi infection. Insect Molecular Biology

450 19, 229-241. doi: 10.1111/j.1365-2583.2009.00978.x

451 Gaines P. J., Brandt K. S., Eisele A. M., Wagner W. P., Bozic C. M. and Wisnewski N.

452 (2002). Analysis of expressed sequence tags from subtracted and unsubtracted 
453 Ctenocephalides felis hindgut and Malpighian tubule cDNA libraries. Insect Molecular

454 Biology 11, 299-306. doi: 10.1046/j.1365-2583.2002.00337.x

455 Greene W.K., Macnish M.G., Rice K.L. and Thompson, R.C.A. (2015). Identification of 456 genes associated with blood feeding in the cat flea,Ctenocephalides felis. Parasites and 457 Vectors 8, 368. doi: 10.1186/s13071-015-0972-5

458 Henry K. M., Jiang J., Rozmajzl P. J., Azad A. F., Macaluso K. R. and Richards A. L. 459 (2007). Development of quantitative real-time PCR assays to detect Rickettsia typhi and 460 Rickettsia felis, the causative agents of murine typhus and flea-borne spotted fever. Molecular 461 and Cellular Probes 21, 17-23.

Huggett J., Dheda K., Bustin S. and Zumla A. (2005). Real-time RT-PCR normalisation; strategies and considerations. Genes and Immunity 6, 279-284. doi: 10.1038/sj.gene.6364190 to different mammalian bloods. Medical and Veterinary Entomology 29, 171-177. doi: $10.1111 /$ mve. 12100

Kidd M., Nadler B., Mane S., Eick G., Malfertheiner M., Champaneria M., Pfragner R. and Modlin I. (2007). GeneChip, geNorm, and gastrointestinal tumors: Novel reference

470 genes for real-time PCR. Physiological Genomics 30, 363-370. doi: 10.1152/physiolgenomics.00251.2006 
475 Li R., Wang S., Wu Q., Yang N., Yang X., Pan H., Zhou X., Bai L., Xu B., Zhou X. and

476 Zhang Y. (2013). Reference gene selection for qRT-PCR analysis in the sweetpotato

477 whitefly, Bemisia tabaci (Hemiptera: Aleyrodidae). PLoS ONE 8, e53006. doi:

$478 \quad 10.1371$ journal.pone.0053006

Misof B., Liu S., Meusemann K., Peters R. S., Donath A., Mayer C., Frandsen P. B.,

480 Ware J., Flouri T., Beutel R. G., et al. (2014). Phylogenomics resolves the timing and

481 pattern of insect evolution. Science 346, 763-767. doi: 10.1126/science. 1257570

482

Odhiambo A. M., Maina A. N., Taylor M. L., Jiang J. and Richards A. L. (2014).

483

Development and validation of a quantitative real-time polymerase chain reaction assay

484 specific for the detection of Rickettsia felis and not Rickettsia felis-like organisms. VectorBorne and Zoonotic Diseases 14, 476-481. doi: 10.1089/vbz.2013.1518

Omondi B. A., Latorre-Estivalis J. M., Oliveira I. H. R., Ignell R. and Lorenzo M. G.

487 (2015). Evaluation of reference genes for insect olfaction studies. Parasites \& Vectors 8: 243. doi: $10.1186 / \mathrm{s} 13071-015-0862-\mathrm{x}$

Pan M. L., Bell W. J. and Telfer W. H. (1969). Vitellogenic blood protein synthesis by 490 insect fat body. Science 165, 393-394.

491 Pfaffl M. W., Tichopad A., Prgomet C. and Neuvians T. P. (2004). Determination of 492 stable housekeeping genes, differentially regulated target genes and sample integrity: 493 BestKeeper - Excel-based tool using pair-wise correlations. Biotechnology Letters 26, 509494515.

496 F., Francischetti I. M. B. and Macaluso K. R. (2012). An insight into the 
497 sialotranscriptome of the cat flea, Ctenocephalides felis. PLoS ONE 7, e44612. doi:

498 doi:10.1371/journal.pone.0044612

499

Rust M. K. and Dryden M. W. (1997). The biology, ecology, and management of the cat 500 flea. Annual Review of Entomology 42, 451-473.

501 Scharlaken B., de Graaf D., Goossens K., Brunain M., Peelman L. J. and Jacobs F. J. 502 (2008). Reference gene selection for insect expression studies using quantitative real-time 503 PCR: The head of the honeybee, Apis mellifera, after a bacterial challenge. Journal of Insect 504 Science 8, 33. doi: 10.1673/031.008.3301

505 Shakeel M., Zhu X., Kang T., Wan H. and Li J. (2015). Selection and evaluation of 506 reference genes for quantitative gene expression studies in cotton bollworm, Helicoverpa 507 armigera (Lepidoptera: Noctuidae). Journal of Asia-Pacific Entomology 18, 123-130. doi:

$508 \quad$ 10.1016/j.aspen.2015.01.001

509 Tan Q. Q., Zhu L., Li Y., Liu W., Ma W. H., Lei C. L. and Wang X. P. (2015). A de Novo 510 transcriptome and valid reference genes for quantitative real-time PCR in Colaphellus

511 bowringi. PLoS ONE 10, e0118693. doi: 10.1371/journal.pone.0118693

512 Teng X., Zhang Z., He G., Yang L. and Li F. (2012). Validation of reference genes for 513 quantitative expression analysis by real-time RT-PCR in four lepidopteran insects. Journal of $514 \quad$ Insect Science 12:60. doi:10.1673/031.012.6001

515 Thellin O., Zorzi W., Lakaye B., De Borman B., Coumans B., Hennen G., Grisar T., 516 Igout A. and Heinen E. (1999). Housekeeping genes as internal standards: Use and limits. 517 Journal of Biotechnology 75, 291-295. 
518 Traversa D. (2013). Fleas infesting pets in the era of emerging extra-intestinal nematodes.

519 Parasites and Vectors 6:59. doi: 10.1186/1756-3305-6-59

520 Vandesompele J., De Preter K., Pattyn F., Poppe B., Van Roy N., De Paepe A. and

521 Speleman F. (2002). Accurate normalization of real-time quantitative RT-PCR data by

522 geometric averaging of multiple internal control genes. Genome Biology

523 3, RESEARCH0034.

524 Winnebeck E. C., Millar C. D. and Warman G. R. (2010). Why does insect RNA look

525 degraded? Journal of Insect Science 10:159. doi: insectscience.org/10.159.

526 Zhai Y., Lin Q., Zhou X., Zhang X., Liu T. and Yu Y. (2014). Identification and validation

527 of reference genes for quantitative real-time PCR in Drosophila suzukii (Diptera:

528 Drosophilidae). PloS ONE 9, e106800. doi: 10.1371/journal.pone.0106800.

529

530

531 


\section{Table 1. Candidate reference genes assessed for stability.}

$533{ }^{\mathrm{a}} \mathrm{Tm}$, melting temperature for oligos; ${ }^{\mathrm{b}} \mathrm{E}$, efficiency of primers, assessed by standard curve

534 slope. SD calculated for efficiencies between runs.

\begin{tabular}{|c|c|c|c|c|c|}
\hline Transcript Name & Function & Oligo Sequence & $\begin{array}{l}\text { Product } \\
\text { size (bp) }\end{array}$ & $\operatorname{Tm}\left({ }^{\circ} \mathrm{C}\right)^{\mathrm{a}}$ & $\begin{array}{l}\mathrm{E} \pm \mathrm{SD} \\
(\%)^{\mathrm{b}}\end{array}$ \\
\hline $\begin{array}{l}\text { 18S ribosomal RNA } \\
\text { gene }(18 \mathrm{~S})\end{array}$ & $\begin{array}{l}\text { Structural protein } \\
\text { in ribosome }\end{array}$ & $\begin{array}{l}\text { F: CCTGCGGCTTAATTTGACTC } \\
\text { R: AGACAAATCGCTCCACCAAC }\end{array}$ & 135 & $\begin{array}{l}59.8 \\
60.1\end{array}$ & $94.1 \pm 5.1$ \\
\hline $\begin{array}{l}\text { 28S ribosomal RNA } \\
\text { gene }(28 \mathrm{~S})\end{array}$ & $\begin{array}{l}\text { Structural protein } \\
\text { in ribosome }\end{array}$ & $\begin{array}{l}\text { F: AAACGGTCCTTGTGACTTGG } \\
\text { R: TCTGAGCTGACCGTTGAATG }\end{array}$ & 136 & $\begin{array}{l}60 \\
60\end{array}$ & $92.7 \pm 2.6$ \\
\hline$\beta$-Actin (Act) & $\begin{array}{c}\text { Cytoskeletal } \\
\text { structure }\end{array}$ & $\begin{array}{l}\text { F: AGGAATTGCTGACCGTATGC } \\
\text { R: TTGGAAGGTGGATAGGGATG }\end{array}$ & 139 & $\begin{array}{l}60.1 \\
59.7\end{array}$ & $97.5 \pm 1.8$ \\
\hline $\begin{array}{l}\text { Muscle specific actin } \\
\text { (DLAct) }\end{array}$ & $\begin{array}{l}\text { Cytoskeletal } \\
\text { structure }\end{array}$ & $\begin{array}{c}\text { F: GGTCGGTATGGGACAAAAGGAC } \\
\text { R: GTAGATTGGGACGGTGTGAGAGAC }\end{array}$ & 367 & $\begin{array}{l}59.9 \\
62.3\end{array}$ & $83.5 \pm 1.3$ \\
\hline $\begin{array}{l}\text { Elongation factor } 1 \alpha \\
\qquad(\mathrm{Ef})\end{array}$ & Translation & $\begin{array}{l}\text { F: TCGTACTGGCAAATCCACAG } \\
\text { R: CATGTCACGGACAACGAAAC }\end{array}$ & 145 & $\begin{array}{l}59.7 \\
60\end{array}$ & $95.3 \pm 4.8$ \\
\hline Glyceraldehyde 3 & & & & 59.8 & \\
\hline $\begin{array}{c}\text { phosphate } \\
\text { dehydrogenase } \\
\text { (GAPDH) }\end{array}$ & Glycolysis & $\begin{array}{l}\text { F: ACCCAAAAGACTGTGGATGG } \\
\text { R: CGGAATGACTTTGCCTACAG }\end{array}$ & 117 & 58.4 & $91.4 \pm 1.5$ \\
\hline $\begin{array}{l}\text { Heat shock protein } 22 \\
\text { (HSP) }\end{array}$ & Stress response & $\begin{array}{l}\text { F: ACCCAATGCGTCTTATGGAC } \\
\text { R: TAATAACCGCCACGGAAGAG }\end{array}$ & 103 & $\begin{array}{l}59.8 \\
60.1\end{array}$ & $93.7 \pm 2.3$ \\
\hline $\begin{array}{l}\text { NADH dehydrogenase/ } \\
\text { ubiquinone reductase } \\
\text { (NADH) }\end{array}$ & $\begin{array}{c}\text { Respiratory chain } \\
\text { enzyme }\end{array}$ & $\begin{array}{l}\text { F: GTCGCTGGTGTAGATGATCTTG } \\
\text { R: TTCGACGTTAAGCACCACAG }\end{array}$ & 133 & 59.8 & $90.7 \pm 16.7$ \\
\hline $\begin{array}{l}\text { 60S ribosomal protein } \\
\text { L19 (RPL19) }\end{array}$ & $\begin{array}{l}\text { Structural protein } \\
\text { in ribosome }\end{array}$ & $\begin{array}{l}\text { F: TACAGCTAATGCCCGTACACC } \\
\text { R: TTCAACAAACGCCTCAGGAC }\end{array}$ & 72 & $\begin{array}{l}60 \\
61.2\end{array}$ & $91.7 \pm 1.1$ \\
\hline$\alpha$-Tubulin ( $\alpha$ Tub) & $\begin{array}{c}\text { Cytoskeletal } \\
\text { structure }\end{array}$ & $\begin{array}{l}\text { F: AACTATTGGAGGCGGTGATG } \\
\text { R: TTGACGGTATGTTCCAGTGC }\end{array}$ & 125 & $\begin{array}{c}60 \\
59.6\end{array}$ & $91.6 \pm 3.4$ \\
\hline Vitellogenin & Reproduction & $\begin{array}{l}\text { F: CAAGAATCCAGCTCCTCCAG } \\
\text { R: ACGGATGCTGAAGCAGAGTT }\end{array}$ & 204 & $\begin{array}{c}59.9 \\
60\end{array}$ & $91.2 \pm 2.0$ \\
\hline
\end{tabular}




\section{Table 2. Rankings of candidate reference genes}

$537 \mathrm{M}=$ average expression stability (geNorm), $\mathrm{SV}=$ stability value (Normfinder), $\mathrm{SD} \pm$

$538 \mathrm{CP}=$ standard deviation \pm crossing point $($ Bestkeeper $), *=$ not considered a suitable

539 reference gene by this programme. Overall ranking is a based on a points-based

540 system to combine the rankings from all programmes used. All rankings are stated

541 from most stable (1) to least stable (10).

542

\begin{tabular}{|c|c|c|c|c|c|c|c|}
\hline \multicolumn{8}{|c|}{ Developmental Stages } \\
\hline Ranking & GeNorm & M & Normfinder & SV & Bestkeeper & $\mathrm{SD} \pm \mathrm{CP}$ & Overall Ranking \\
\hline 1 & $\begin{array}{c}\text { Ef/ } \\
\text { RPL19 }\end{array}$ & 0.132 & RPL19 & 0.27 & $18 \mathrm{~S}$ & 0.54 & Ef \\
\hline 2 & - & & Ef & 0.276 & GAPDH & 0.63 & RPL19 \\
\hline 3 & Act & 0.149 & Act & 0.29 & Ef & 0.76 & Act \\
\hline 4 & aTub & 0.257 & GAPDH & 0.318 & Act & 0.8 & GAPDH \\
\hline 5 & GAPDH & 0.441 & aTub & 0.365 & RPL19 & 0.88 & $18 \mathrm{~S}$ \\
\hline 6 & DLAct & 0.626 & DLAct & 0.558 & DlAct & 0.91 & aTub \\
\hline 7 & $18 \mathrm{~S}$ & 0.845 & $18 \mathrm{~S}$ & 0.902 & $28 \mathrm{~S}$ & 0.97 & DlAct \\
\hline 8 & HSP & 1.034 & HSP & $1.054^{*}$ & aTub & 0.98 & 28S / HSP \\
\hline 9 & $28 \mathrm{~S}$ & 1.203 & $28 \mathrm{~S}$ & $1.145^{*}$ & HSP & $1.89 *$ & - \\
\hline \multicolumn{8}{|c|}{$\underline{\text { Males vs Females }}$} \\
\hline Ranking & GeNorm & M & Normfinder & SV & Bestkeeper & $\mathrm{SD} \pm \mathrm{CP}$ & Overall Ranking \\
\hline 1 & $\begin{array}{c}\text { GAPDH / } \\
\text { RPL19 }\end{array}$ & 0.114 & GAPDH & 0.144 & DlAct & 0.51 & GAPDH \\
\hline 2 & - & - & Ef & 0.188 & Ef & 0.54 & Ef \\
\hline 3 & Ef & 0.142 & Act & 0.197 & RPL19 & 0.61 & RPL19 \\
\hline 4 & Act & 0.196 & RPL19 & 0.216 & GAPDH & 0.7 & Act \\
\hline 5 & HSP & 0.408 & HSP & 0.412 & $28 \mathrm{~S}$ & 0.76 & 28S / DLAct / HSP \\
\hline 6 & aTub & 0.497 & $28 \mathrm{~S}$ & 0.414 & Act & 0.78 & - \\
\hline 7 & $28 \mathrm{~S}$ & 0.629 & aTub & 0.469 & $18 \mathrm{~S}$ & $1.21 *$ & - \\
\hline 8 & DLAct & 0.73 & $18 \mathrm{~S}$ & 0.491 & HSP & $1.23 *$ & aTub \\
\hline 9 & $18 \mathrm{~S}$ & 0.83 & DLAct & 0.51 & aTub & $1.34 *$ & $18 \mathrm{~S}$ \\
\hline
\end{tabular}




\section{$\underline{\text { Fed Adults vs Unfed Adults }}$}

$\begin{array}{cccccccc}\text { Ranking } & \text { GeNorm } & \text { M } & \text { Normfinder } & \text { SV } & \text { Bestkeeper } & \text { SD } \pm \text { CP } & \text { Overall Ranking } \\ \mathbf{1} & \text { Act / Ef } & 0.112 & \text { GAPDH } & 0.092 & \text { 28S } & 0.27 & \text { RPL19 } \\ \mathbf{2} & - & - & \text { RPL19 } & 0.147 & \text { GAPDH } & 0.29 & \text { Ef / GAPDH } \\ \mathbf{3} & \text { RPL19 } & 0.141 & \text { aTub } & 0.16 & \text { RPL19 } & 0.42 & - \\ \mathbf{4} & \text { HSP } & 0.163 & \text { Ef } & 0.206 & \text { Ef } & 0.47 & \text { aTub } \\ \mathbf{5} & \text { aTub } & 0.195 & \text { DLAct } & 0.23 & \text { HSP } & 0.51 & \text { Act } \\ \mathbf{6} & \text { GAPDH } & 0.221 & \text { Act } & 0.236 & \text { aTub } & 0.52 & \text { HSP } \\ \mathbf{7} & \text { DLAct } & 0.266 & \text { HSP } & 0.241 & \text { Act } & 0.54 & 28 \mathrm{~S} \\ \mathbf{8} & 28 \mathrm{~S} & 0.383 & 28 \mathrm{~S} & 0.431 & 18 \mathrm{~S} & 0.57 & \text { DLAct } \\ \mathbf{9} & 18 \mathrm{~S} & 0.489 & 18 \mathrm{~S} & 0.491 & \text { DLAct } & 0.71 & \text { 18S }\end{array}$

\section{$\underline{\text { Insecticide Treated vs Untreated }}$}

\begin{tabular}{|c|c|c|c|c|c|c|c|}
\hline Ranking & GeNorm & M & Normfinder & SV & Bestkeeper & $\mathrm{SD} \pm \mathrm{CP}$ & Overall Ranking \\
\hline 1 & $\begin{array}{c}\text { Act / } \\
\text { RPL19 }\end{array}$ & 0.104 & Ef & 0.035 & Act & 0.22 & Act / RPL19 \\
\hline 2 & - & - & aTub & 0.075 & RPL19 & 0.25 & - \\
\hline 3 & GAPDH & 0.337 & HSP & 0.135 & GAPDH & 0.45 & $\mathrm{Ef}$ \\
\hline 4 & HSP & 0.459 & DLAct & 0.138 & Ef & 0.63 & GAPDH \\
\hline 5 & $\mathrm{Ef}$ & 0.502 & GAPDH & 0.252 & HSP & 0.66 & HSP \\
\hline 6 & aTub & 0.597 & RPL19 & 0.408 & aTub & $1.07 *$ & aTub \\
\hline 7 & DLAct & 0.734 & Act & 0.416 & DLAct & $1.45^{*}$ & DLAct \\
\hline 8 & $28 \mathrm{~S}$ & 1.115 & $28 \mathrm{~S}$ & 0.581 & $28 \mathrm{~S}$ & $2.21 *$ & $28 \mathrm{~S}$ \\
\hline 9 & $18 \mathrm{~S}$ & $1.533^{*}$ & $18 \mathrm{~S}$ & 0.952 & $18 \mathrm{~S}$ & $2.82 *$ & $18 \mathrm{~S}$ \\
\hline
\end{tabular}

543 
549 Fig. 1 Electopherogram assessment of RNA quality for pierced and unpierced C. felis 550 specimens stored at room temperature for $\mathbf{0 , 3}$ or 10 days.

551 Total RNA was extracted from pierced or unpierced C. felis larvae (Fig. 1A) or adults (Fig. 552 1B) which had been stored in RNAlater at room temperature for 0, 3 or 10 days. 40-120 ng of 553 RNA were run on the Agilent Bioanalyzer 2100 microfluidics gel analysis platform to 554 determine RNA quality.

555

556 Figure 2. Average cycle thresholds of candidate reference genes.

557 The boxplot represents median, and indicates 25th and 75th percentile. Whiskers represent 558 the 10th and 90th percentiles. Black dots indicate outliers. Cq values for all tested samples ( $\mathrm{n}$ $559=30)$ across all groups $(C$. felis developmental groups, sexes, feeding statuses and insecticide 560 treatment statuses).

561

562 Figure 3. Average expression stability of candidate reference genes

563 Values for average expression stability (M) as calculated by geNorm (v. 3.4) by pairwise

564 comparison and stepwise exclusion of the least stable reference gene, for four group

565 comparisons: (A) C. felis developmental stages (larvae, pupae, unfed adults, fed adults); (B)

566 feeding statuses (unfed and fed adults); (C) sexes (males and females); (D) Insecticide-

567 treatment statuses (treated with $1 \mu \mathrm{M}$ selamectin or untreated fed adults).

568

569 570 reference genes

Figure 4. Pairwise variation values for assessment of necessary number of

571 geNorm (v. 3.4) calculated pairwise variation (V) for assessment of sufficient number of

572 reference genes for accurate normalization in each of four group comparisons of C. felis:

573 developmental stages (larvae, pupae, unfed adults, fed adults); feeding statuses (unfed and

574 fed adults); sexes (males and females); insecticide-treatment statuses (treated with $1 \mu \mathrm{M}$

575 selamectin or untreated fed adults). $\mathrm{V}<0.15$ indicates inclusion of a further reference gene is

576 of negligible benefit.

577

578 Figure 5. Validation of reference genes by testing vitellogenin $\mathrm{C}$ expression levels.

579 Vitellogenin C levels were measured in female relative to male fed $C$. felis adults.

580 Vitellogenin C expression levels were assessed relative to single most (GAPDH, Ef) or least

581 (18S) stable reference genes or combinations of the two (Ef + GAPDH) or three (Ef +

582 GAPDH + RPL19) most stable reference genes. Data are means +/- SEM, $\mathrm{n}=3$. 


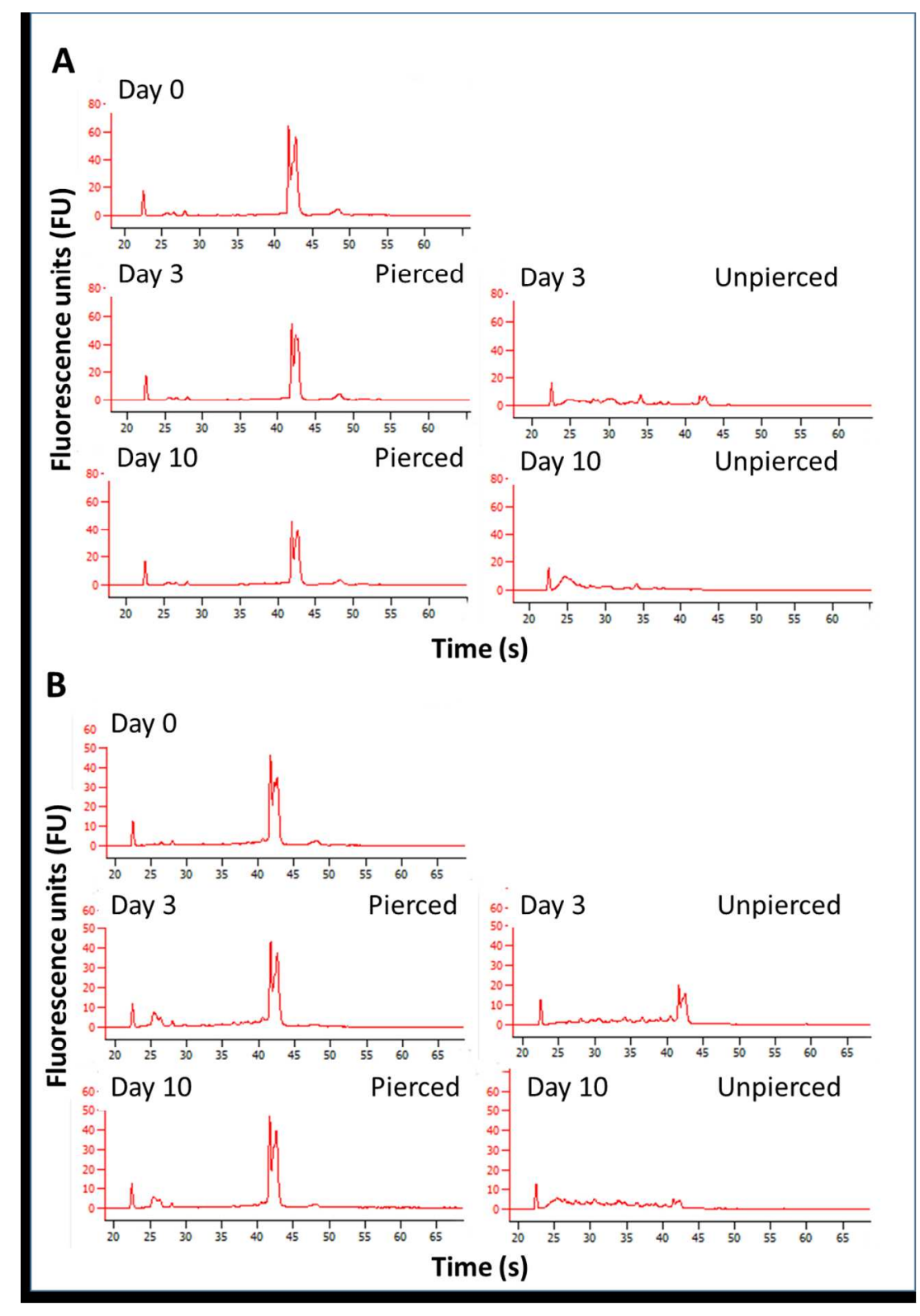

$401 \times 578 m m(72 \times 72$ DPI $)$ 


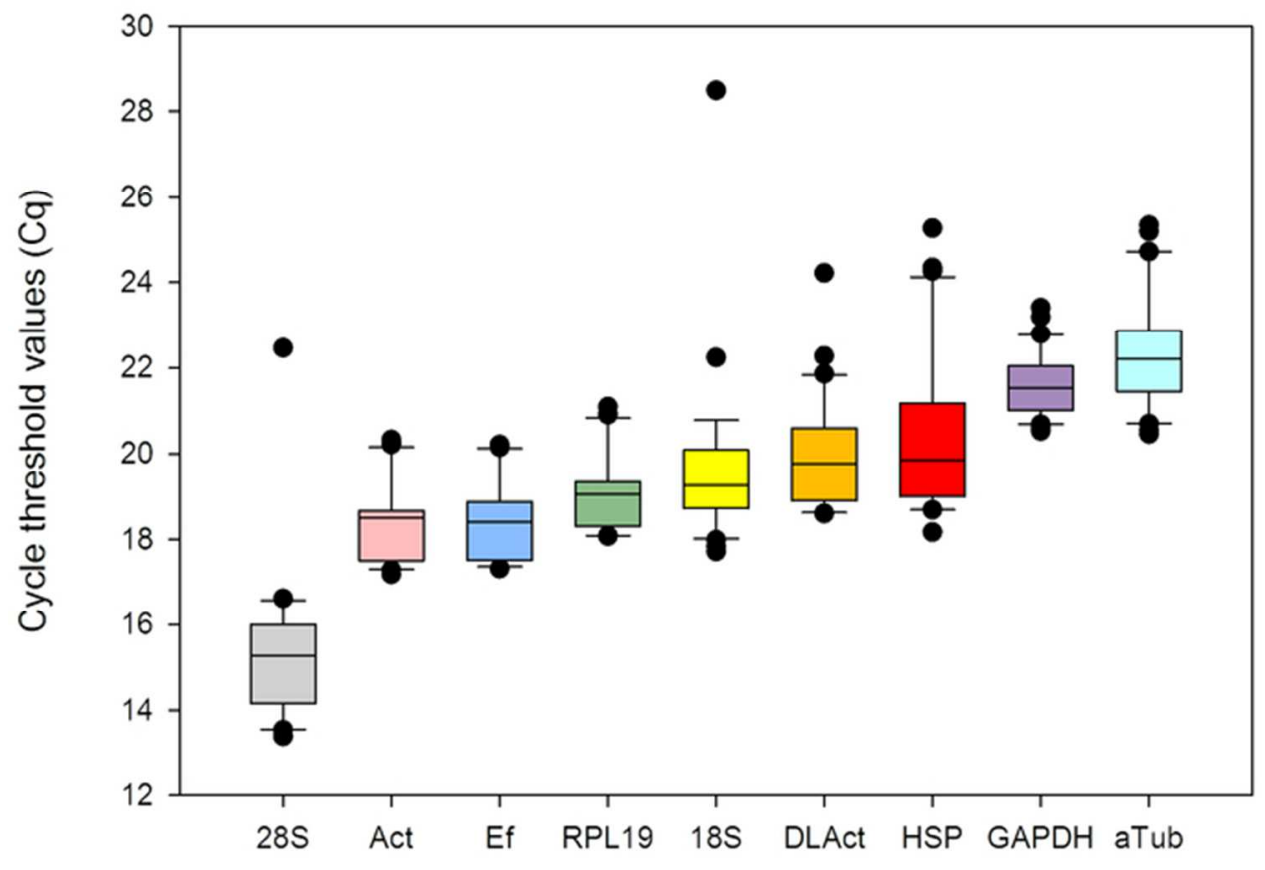

$59 \times 44 \mathrm{~mm}(300 \times 300$ DPI $)$ 


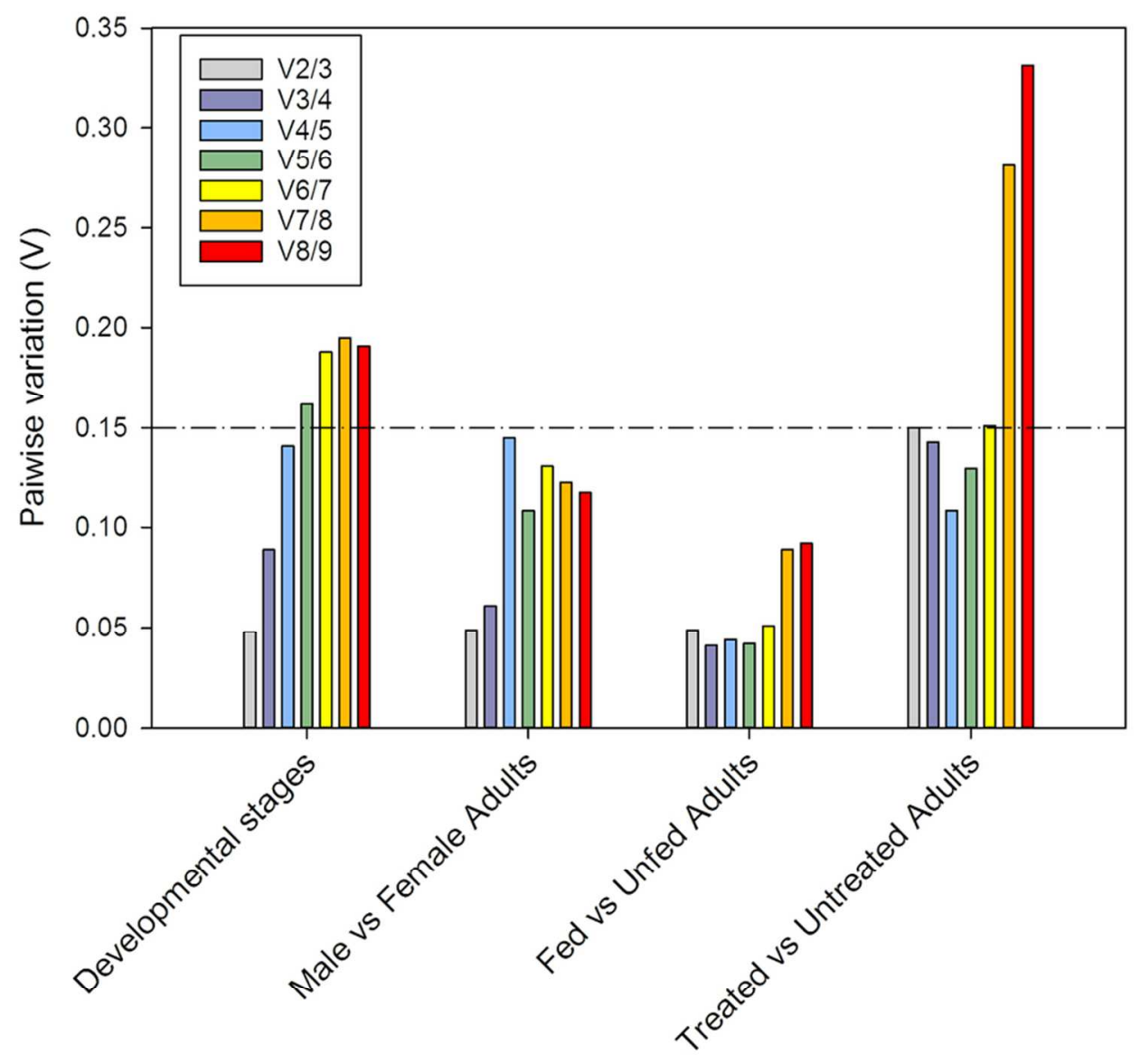

$80 \times 80 \mathrm{~mm}(300 \times 300$ DPI $)$ 


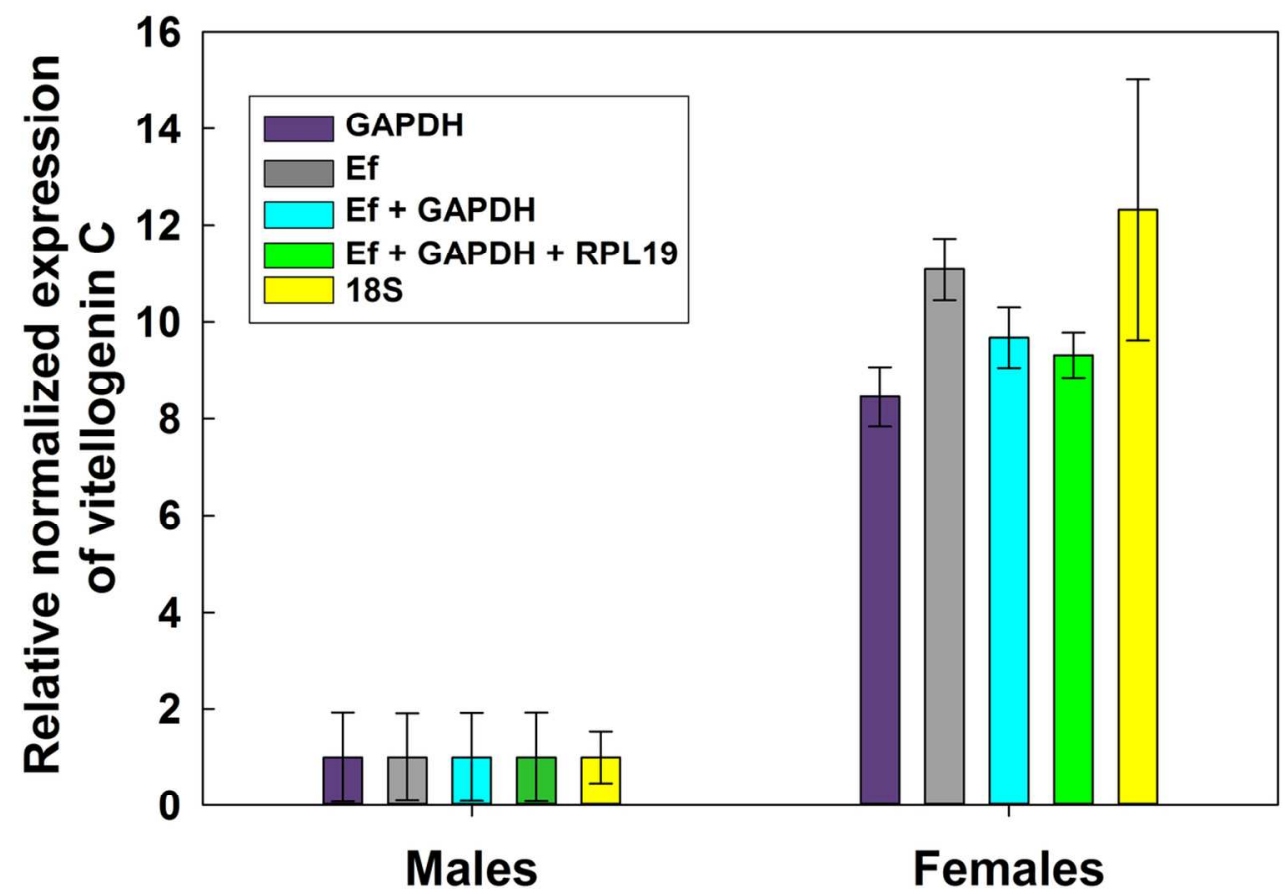

$57 \times 41 \mathrm{~mm}(600 \times 600 \mathrm{DPI})$ 